\title{
African American Preschoolers' Language, Emergent Literacy Skills, and Use of African American English: A Complex Relation
}

\section{Carol McDonald Connor}

Florida State University, Tallahassee, and the Florida Center for Reading Research, Tallahassee

Holly K. Craig University of Michigan, Ann Arbor
Purpose: This study examined the relation between African American preschoolers' use of African American English (AAE) and their language and emergent literacy skills in an effort to better understand the perplexing and persistent difficulties many African American children experience learning to read proficiently. Method: African American preschoolers' $(n=63)$ vocabulary skills were assessed in the fall and their language and emergent literacy skills were assessed in the spring. The relation between students' AAE use and their vocabulary and emergent literacy skills was examined using hierarchical linear modeling (HLM), controlling for fall vocabulary and other child, family, and school variables. Children's use of AAE was examined across two contexts - sentence imitation and oral narrative using a wordless storybook prompt.

Results: There was a significant U-shaped relation between the frequency with which preschoolers used AAE features and their language and emergent literacy skills. Students who used AAE features with greater or lesser frequency demonstrated stronger sentence imitation, letter-word recognition, and phonological awareness skills than did preschoolers who used AAE features with moderate frequency, controlling for fall vocabulary skills. Fewer preschoolers used AAE features during the sentence imitation task with explicit expectations for Standard American English (SAE) or School English than they did during an oral narrative elicitation task with implicit expectations for SAE.

Conclusions: The nonlinear relation between $\mathrm{AAE}$ use and language and emergent literacy skills, coupled with systematic differences in AAE use across contexts, indicates that some preschoolers may be dialect switching between AAE and SAE, suggesting emerging pragmatic/metalinguistic awareness.

KEY WORDS: children, literacy, metalinguistic awareness, phonological awareness, dialects, African American English

$\mathrm{T}$ here is a well-documented and long-standing disparity between the reading levels of African American children and their European American peers. Sixty-one percent of African American children failed to achieve basic reading levels on the 2003 fourth grade National Assessment of Educational Progress compared to 26\% of their White peers (U.S. Department of Education, 2003). This Black-White achievement gap is observable across a broad range of measures of school success, including grade point average, enrollments in special education versus gifted programs, suspension rates, high school graduation rates, 
college enrollments, and so on (Artiles \& ZamoraDuran, 1997; Hoffman \& Llagas, 2003; Ogbu, 2003; Owings \& Magliaro, 1998). It has been suggested that reducing the achievement gap would do more to reduce racial inequality than any other single strategy (Jencks \& Phillips, 1998).

A number of variables have been hypothesized to account for the gap. Family socioeconomic status (SES), classroom characteristics, and early family literacy practices are important factors in literacy development and thus contribute to the academic success of mainstream students. Differences from mainstream patterns have been considered potential risk factors for African American students. Low SES is considered to be a risk factor, and African American students are three times more likely than their mainstream peers to reside in low-income homes (Federal Interagency Forum on Child and Family Statistics [FIFCFS], 2003). Low SES includes the effects of lower family income; maternal/ caregiver education level; limited or poor quality community resources in terms of schools, health care, libraries, and so on; and amounts and quality of home literacy materials and experiences (Brooks-Gunn, Duncan, Klebanov, \& Sealand, 1993; Fazio, Naremore, \& Connell, 1996; Hoffman \& Llagas, 2003; Nettles \& Perna, 1997). Classroom characteristics reflect a complex set of variables as well, and African American students are more likely than their mainstream peers to have poorer quality teachers (Darling-Hammond, 1997; Haycock, Jerald, \& Huang, 2001) and teachers with lower expectations (Ogbu, 2003; Stevenson, Chen, \& Uttal, 1990). In addition, the early family literacy experiences of African American students differ in important ways from their mainstream peers. African American students are more likely to have rich oral storytelling experiences (Ball, 1992) but are less likely than their mainstream peers to engage in daily storybook reading (FIFCFS, 2003), and they first may experience text as environmental forms of print, often with unconventional spellings, as in trademarks (Craig \& Washington, 2004a).

The achievement gap, however, is not explained fully by these sources of influence (Jencks \& Phillips, 1998), and the search for additional factors is an important ongoing target of current research focused on alleviating the gap. Accumulating research is revealing important links between all children's oral language and literacy development (e.g., Craig, Connor, \& Washington, 2003; Loban, 1976; Scarborough, 2001; Storch \& Whitehurst, 2002). A salient language difference between White and many African American students is the dialect they speak and bring to the task of literacy acquisition. The purpose of this study is to contribute to the search for important influences on achievement by examining links between African American students' oral language and emergent literacy skills.
Standard American English (SAE; also called Standard English or School English) is the primary dialect spoken by many White students and teachers and it is the dialect used in most books and texts children encounter in school. African American English (AAE; also called Black Language, Black English, African American Vernacular English, and Ebonics) is the primary dialect spoken by many African American students (Connor, 2002; Craig \& Washington, 2006; Manning \& Baruth, 2003; Perry \& Delpit, 1998). Children's AAE is characterized by systematic differences from SAE in morphosyntactic and phonological features, which distribute at different rates based on the student's grade (younger children use more features than do older children) (Craig \& Washington, 2004b; Isaacs, 1996), gender (boys use more AAE than do girls), SES (children from low SES families tend to use more AAE than do children from middle SES families) (Horton-Ikard \& Miller, 2004; J. A. Washington, Craig, \& Connor, 1998), and discourse context (Thompson, Craig, \& Washington, 2004; J. A. Washington, Craig, \& Kushmaul, 1998).

\section{AAE Use and Reading}

The potential role of AAE feature differences from SAE in the reading achievement of African American students was the focus of considerable research during the 1970s and early 1980s and again recently. Two theories were proposed: (a) that teachers had negative perceptions and reduced expectations for students who used AAE (Goodman \& Buck, 1973) and (b) that there was a mismatch between the dialect children spoke and the dialect they encountered at school and in text. An emerging theory based on recent research is (c) the dialect awareness/shifting theory.

Teacher bias theory. Research supporting the teacher bias theory revealed that teachers' perceptions of children's abilities and how they interacted with them were related to students' use of AAE (Brown, 1980; Shields, 1979; V. M. Washington \& Miller-Jones, 1989). This hypothesis would suggest that children who used AAE features more frequently would have weaker emergent literacy skills by the end of the school year than would children who used AAE features less frequentlya negative linear relation.

Mismatch hypothesis. Researchers also theorized that there was a mismatch between the SAE children encounter in text and the classroom and the AAE they speak, which offers a barrier or additional hurdle to literacy acquisition (Cecil, 1988) and which would also suggest a negative linear relation between AAE and reading. Early studies were hampered by the lack of information about child AAE feature taxonomies and their distributional characteristics. They consistently observed student production of $\mathrm{AAE}$ while reading text 
written in SAE (Harber, 1982; Rystrom, 1973-1974; Steffensen, Reynolds, McClure, \& Guthrie, 1982). The research designs involved selecting just a few features known to characterize the AAE features used by adults and probing for specific links to reading scores or teacher perception. Across a broad set of studies, no significant relations were observed between production of selected morphosyntactic and phonological features of AAE and reading performances (Gemake, 1981; Harber, 1977; Hart, Guthrie, \& Winfield, 1980; Melmed, 1973; Rystrom, 1973-1974; Seymour \& Ralabate, 1985; Simons \& Johnson, 1974).

However, research accumulating over the past decade has more fully described AAE features children use, which include 40 or more morphosyntactic and phonological features (Craig, Thompson, Washington, \& Potter, 2003; Craig \& Washington, 2002; Horton-Ikard \& Miller, 2004; Oetting \& McDonald, 2001). Recent research has revealed that rates of AAE feature production are especially informative for probing systematic variations in $\mathrm{AAE}$ use relative to child variables, such as gender and SES (Horton-Ikard \& Miller, 2004; J. A. Washington \& Craig, 1998), linguistic sophistication (Charity, Scarborough, \& Griffin, 2004; Craig \& Washington, 1995; Jackson \& Roberts, 2001), grade, and discourse context (Craig \& Washington, 2004a; Thompson et al., 2004), and for more distal sources of influence such as community and classroom (Wolfram, Adger, \& Christian, 1999). Examples of these AAE features are provided in Appendix A.

Using this more finely grained representation of $\mathrm{AAE}$ use, two recent studies have indicated that AAE feature production rates are strongly negatively associated with reading achievement for African American students. Craig and Washington (2004a) found that African American first through fifth graders who used AAE features less frequently in their spontaneous discourse outperformed children who used AAE features more frequently on measures of reading achievement such as the Metropolitan Achievement Tests (Balow, Farr, \& Hogan, 1992). Moreover, they observed that preschoolers and kindergarteners used AAE features much more frequently than did first through fifth grade students. Similarly, Charity et al. (2004) found that less production of AAE and greater production of SAE during an elicited sentence imitation task was associated with better reading outcomes on the Woodcock Reading Mastery Tests-Revised (Woodcock, 1987) for second through fifth graders.

Dialect awareness/shifting theory. Considered together, these studies (Charity et al., 2004; Craig \& Washington, 2004a) offer a third hypothesis that holds that that greater knowledge of SAE appears advantageous for the processes involved in reading acquisition by African American students. In both studies, the authors suggested that dialect shifting or dialect awareness might be associated with students' stronger literacy achievement. Neither study design, however, could illuminate whether this explanation was superior to the mismatch between the AAE and SAE hypothesis (Baratz, 1969; Labov, 1995) or the teacher perceptions and expectations hypothesis in explaining these findings. Additional indirect support for the dialect awareness/ shifting hypothesis is provided in a study that examined third grade students' use of AAE across language and literacy tasks (Thompson et al., 2004). Overall, children were observed to use fewer features of AAE in the reading and writing tasks than in the oral language task. However, the relation of students' AAE use and reading proficiency was not explored.

\section{Purpose of the Study}

The purpose of this study was to investigate whether there might be a relation between AAE and emergent literacy for very young students who have had limited experience with formal school and with written text. We attempted to elucidate the mismatch hypothesis and the dialect awareness/shifting hypothesis. We also attempted to rule out the teacher bias hypothesis for our specific teacher participants during our repeated classroom observations of teacher-child interactions and through teacher surveys designed to assess teachers' perceptions of their students and their own efficacy in meeting their needs. These results are provided in Appendix A.

A relation between $\mathrm{AAE}$ use and emergent literacy skills is important to consider because research reveals that the language and literacy skills children bring to school explain a substantial proportion of variability in their later reading skills. Children are more likely to be stronger readers in later grades if, at the beginning of preschool or kindergarten, they demonstrate larger vocabularies (Catts, Fey, Zhang, \& Tomblin, 1999; Morrison, Bachman, \& Connor, 2005; Scarborough, 2001), stronger letter and word recognition, stronger phonological awareness skills (National Reading Panel, 2000; Reynolds \& Ou, 2004; Snow, Burns, \& Griffin, 1998), and better sentence imitation skills (Catts et al., 1999; Rego \& Bryant, 1993), which likely assesses children's linguistic maturity (Newcomer \& Hammill, 2000) and metalinguistic awareness more generally (Catts et al., 1999; Charity et al., 2004). Senechal and LeFevre (2002) noted that language, phonological awareness, and emergent reading may be conceptualized as distinct constructs. The relation of children's AAE use to any of these key outcomes might have implications for their later success learning to read and, in this study, we investigated the relation between vocabulary, metalinguistic awareness, and letter-word 
recognition and children's AAE use. Moreover, we anticipated that this relation may be more complex than the negative linear trend observed in other studies.

Accumulating research also reveals multiple sources of influence on the development of these key literacy predictors. These include sociocultural, home and community influences (Bronfenbrenner, 1986; Morrison et al., 2005; NICHD-ECCRN, 2002, 2004), and preschool experiences (Barnett, 1995; Morrison et al., 2005; Nelson, Benner, \& Gonzalez, 2003). Therefore, we also examined the relations among children's language and emergent literacy, AAE use, and child, family, teacher, and classroom variables, including the classroom and school district children attended, parent education, and students' age, gender, and vocabulary skills at the beginning of the school year.

In a more direct examination of potential dialectshifting, we also asked whether young children might shift between AAE and SAE as the context and expectations for AAE and SAE changed. It has been conjectured that contexts for speaking that are similar to the kinds of situations children encounter in the classroom (e.g., reading aloud) are more likely to elicit fewer AAE features and to elicit more features associated with SAE typically used in school than are more informal speaking contexts (Charity et al., 2004; Craig, Washington, \& Connor, 2000; Washington, Craig, \& Kushmaul, 1998). What is not clear is whether children as young as preschoolers will change their use of AAE and SAE as demands for school forms of English increase.

We examined preschoolers' AAE use across two contexts that students might encounter in the classroom but that varied in expectations for use of SAE: (a) we selected an age appropriate literacy task as our context for language sampling and examined preschoolers' use of AAE during an oral narrative using a wordless storybook prompt (Berman \& Slobin, 1994) and (b) we examined children's use of AAE during the administration of the Test of Language Development-Second Edition: Primary (TOLD-2:P) Sentence Imitation subtest (Newcomer \& Hammill, 1988). In the first task, children provide an oral narrative as they "read" a wordless storybook using the pictures to guide their narrative. This task has been used with children across ages and across cultures and typically will elicit the more formal language structures children find in books (Berman \& Slobin, 1994; Sulzby, 1985). However, the expectations for school forms of English are less salient than, for example, our second context, the TOLD-2:P Sentence Imitation subtest. The second context, while primarily an index of linguistic proficiency, also carries a high and explicit expectation for SAE inasmuch as children are told to repeat exactly the sentences they hear and these sentences are all presented using SAE.
It has been suggested that children who have less familiarity with SAE will more likely diverge from the presented SAE forms and will use AAE forms as they perform this task (Baratz, 1969; Charity et al., 2004).

To summarize, the following research questions were posed: (a) what is the relation between preschoolers' AAE use and their language and emergent literacy skills, taking into account home and classroom sources of influence, and (b) do preschoolers use AAE with more or less frequency when provided with explicit compared to implicit expectations for SAE?

\section{$\overline{\text { Method }}$ Participants Children}

Sixty-three African American children, all of whom were enrolled in preschool Head Start and state-funded intervention programs for children at risk for academic underachievement, participated in this study. The children were participating in a larger study of child, family, home, classroom, and cultural-linguistic influences on preschoolers' developing literacy (Connor, 2002). Participants, their families, and their preschool teachers ( $n=10$ classrooms) were recruited from preschool classrooms in two different school districts. All children attending these preschool classrooms were eligible to participate in the larger study; $81 \%$ of parents returned signed letters of consent. Four of the 109 child participants left the school district before the end of the study, 23 spoke English as a second language, and 19 were White. The remaining children $(n=63)$, all of whom were African American or biracial, participated in this study. Descriptive information is provided in Table 1. With regard to caregiver educational levels, only 8 of 56 parents reported completing college; all except 1 completed high school. Children did not vary by classroom or school district on a culture-fair nonverbal test of cognitive ability, the Kaufman Assessment Battery for Children, Triangle subtest (Kaufman \& Kaufman, 1983).

\section{Classrooms and Teachers}

The preschool interventions included Head Start and the state School Readiness Program. Head Start is a federally funded program designed to support children who may be at risk for academic underachievement because their family lives in poverty. Other risk factors may exist. However, for most programs, family poverty is the primary criterion for enrollment in the classroom. The state-funded preschool programs were designed for children who were eligible for Head Start or who had 
Table 1. Descriptive information on child participants.

\begin{tabular}{|c|c|c|c|c|}
\hline No. of children & 43 & 20 & 63 & \\
\hline No. of classrooms & 4 & 6 & 10 & \\
\hline$\%$ of African American students/classroom (M) & $70.23^{*}$ & $29.63^{*}$ & $45.87(30.99)$ & \\
\hline No. of girls & 22 & 11 & 33 & \\
\hline KABC (Triangle Task, SS $M=10$ ) & 10.38 & 10.7 & $10.5(2.6)$ & \\
\hline Mean fall vocabulary (raw score) & $44.87^{*}$ & $54.60^{*}$ & $47.57(13.59)$ & $94(14)$ \\
\hline Mean fall vocabulary (age equivalent) & $3 ; 7$ & $4 ; 4$ & $3 ; 10$ & \\
\hline Mean number of $\mathrm{AAE}$ tokens used in oral narrative & 7.3 & 5.6 & $6.8(6)$ & \\
\hline Mean spring \%DDM (AAE features/word) on oral narrative & 3.81 & 2.88 & $3.51(2.72)$ & \\
\hline Mean spring vocabulary (W score) & 466 & 467 & $466.32(8.45)$ & $101.25(8.6)$ \\
\hline Mean Sentence Imitation no credit for AAE (age equivalent, years) & & & 4.25 & \\
\hline Mean Sentence Imitation credit for AAE (raw score) & 7.1 & 5.4 & $6.56(4.43)$ & $89(23.2)$ \\
\hline Mean Sentence Imitation credit for AAE (age equivalent years) & & & 4.5 & \\
\hline$\%$ of $\mathrm{AAE}$ forms (\%DDM) oral narrative & 3.8 & 2.9 & 3.5 & \\
\hline
\end{tabular}

Note. Except for \% of African American Students per classroom, $t(8)=2.60, p=.032$, and for fall vocabulary, $t(52)=2.47, p=.017$, there was no significant difference by district for any variable $(p<.05$ for children, $p<.10$ for classrooms). $\mathrm{HLM}=$ hierarchical linear modeling; $K A B C=K a u f m a n$ Assessment Battery for Children; AAE = African American English; \%DDM = percent dialect density measure, which is the number of $A A E$ tokens/total number of words in the sample.

${ }^{*} p<.05$ for significant differences between districts.

been identified as at risk for academic underachievement as defined by the existence of at least 2 of 25 specific risk factors, including medical, developmental, family, economic, and environmental indicators. State regulations dictated that at least $50 \%$ of the children in the program must come from low-income homes based on family income.

The Head Start and state-funded half-day preschool programs were located in one of two school districts. The first school district was located on the fringe of a major metropolitan area. Approximately $75 \%$ of the children, district-wide, were African American and approximately $45 \%$ of the students were eligible for participation in the free and reduced price lunch program (Standard and Poor's School Evaluation Services, 2003). The second school district was located in a midsized city within which was located a major university. Although, districtwide, many of the students in this school district were White $(69 \%)$, about $10 \%$ of the students were African American. Approximately 15\% of the students qualified for the free or reduced-price lunch programs.

Five teachers, all of whom were White, each taught two half-day classes, one in the morning and one in the afternoon. All teachers held at least a bachelor's degree and all but one had early childhood credentials. All but one of the teachers had a masters' degree, including the teacher without an early childhood credential. All of the early childhood teachers (Head Start and state-funded) in the urban school district were considered fully credentialed teachers and were part of the district teachers' union. In the midsized city, the state-funded preschool teachers were also considered fully credentialed teachers and belonged to that district's teachers' union. However, the Head Start teacher did not. Her standing in the district was that of a paraprofessional and thus professional development release and other benefits available to district teachers were not available to her.

Observations of teachers and their classrooms using the Early Childhood Environmental Rating Scale (Harms, Clifford, \& Cryer, 1998) revealed that all 10 of the classrooms were of good to excellent quality. Teachers completed surveys that gathered information about their expectations for their students and their self-perceived efficacy teaching them. Analyses revealed that teachers' perceptions of their students' ability to learn did not vary across classrooms, although the ethnic and racial composition of the classrooms did. Nor were perceptions systematically related to students' language and emergent literacy skills or children's AAE 
use, with one exception. Children who used AAE more frequently generally had teachers who perceived them as less disadvantaged.

\section{Student Measures}

Children were assessed during the fall and spring of the school year. The assessments, which were conducted in a quiet area in the school, are described below.

Fall vocabulary. Children's receptive vocabulary was assessed in the fall of the preschool year using the Peabody Picture Vocabulary Test-Third Edition (Dunn \& Dunn, 1997). In this task, children are asked to select increasingly unfamiliar target words from four pictures. Reliability (alpha) for preschool age children is .94 and the standard error of measurement is 4.4.

Spring AAE use and percent dialect density measure. Individual child language samples were elicited following procedures described by Berman and Slobin (1994). Children were provided an opportunity to page through the wordless storybook Frog, Where Are You? (Mayer, 1969) and then asked to "read" the book page by page. There are several advantages offered within this language sampling context. First, this context provides ecological validity inasmuch as the child is "reading" a book, albeit one without text. Additionally, there exists a large body of research on children's oral narratives (Berman \& Slobin, 1994) and emergent storybook readings (Cox, Fang, \& Otto, 1997; Elster, 1994; PurcellGates, McIntyre, \& Freppon, 1995). It was from this task that we sampled children's AAE use with implicit expectations for SAE use.

Transcripts were transcribed orthographically following CHILDES protocols (MacWhinney, 1994). Ten percent of the transcripts were selected at random and transcribed by a certified speech-language pathologist trained in the transcribing procedures. Reliability (number of agreements at the level of the word divided by the number of agreements plus disagreements times 100) was $92 \%$.

From transcripts of the oral narratives elicited using Frog, Where Are You? (Mayer, 1969), morphosyntactic AAE forms were coded using a system developed by Craig and Washington (Craig \& Washington, 1994; Craig, Washington, \& Thompson-Porter, 1998; J. A. Washington \& Craig, 1998; Washington \& Craig, 1994). A description of the features and examples from the language samples are provided in Appendixes A and B. The number of AAE tokens divided by the total number of words in the sample multiplied by 100 provided the percentage of dialect used (percent dialect density measure [DDM]; see also Oetting \& McDonald, 2002). Reliability (for $10 \%$ of the transcripts, number of agreements by two different coders divided by the number of agreements plus disagreements times 100) was $89 \%$.
Spring sentence imitation. The Sentence Imitation subtest of the Test of Language Development-Second Edition: Primary (TOLD-2:P; Newcomer \& Hammill, 1988) was used to assess both morphosyntactic awareness skills (Charity et al., 2004; Tumner, Nesdale, \& Wright, 1987) and syntactic sophistication (Catts, Fey, Zhang, \& Tomblin, 2001), as well as to obtain a sample of children's AAE use with explicit expectations for SAE. In this task, children were read SAE sentences of increasing complexity and were asked to repeat them exactly. If the child failed to imitate the sentence exactly, the item was scored as incorrect. This task has a reported internal consistency (split-half) of .90 and a standard error of measurement of 1.7 for 4-year-olds and .92 and 1.8, respectively, for 5-year-olds.

In addition to the scoring strategy described in the manual, a second score was computed. In this score, items were counted as correct if repetition of the sentence differed from the target only because the child used a recognized feature of AAE (see Appendix A). For example, the target for Item 4 was "Yesterday my aunt forgot their lunch." If the child repeated the sentence as "Yesterday my aunt forgot they lunch", then in standard scoring this would be counted as incorrect. In the alternative scoring scheme, this response would be counted as correct because the only difference from the target was use of the undifferentiated pronoun case (they instead of their), which is a recognized feature of AAE. Administration of items continued until the child reached ceiling using this scoring strategy even if the child reached ceiling using the manual's scoring protocol. The types of AAE features substituted for SAE features were recorded.

Spring vocabulary. The Woodcock-Johnson Tests of Achievement-Third Edition, Picture Vocabulary (Woodcock \& Mather, 2001), a standardized test, was used to assess children's vocabulary. Children were asked to name pictures of increasingly less familiar and more complex words. Raw scores were transformed to $\mathrm{W}$ scores for the analyses. W scores are a variation of the Rasch ability scale and are centered at 500, which represents the achievement of a typical 10-year-old child. The test standardization sample mean is 460.63 for 4-year-old children and $468(S D=16.7, S E M=8.2)$ for 5-year-old children. The median reliability is .81 (McGrew, Werder, \& Woodcock, 1991).

Spring letter-word recognition. The WoodcockJohnson Tests of Achievement-Third Edition, Letter and Word Identification Test (Woodcock \& Mather, 2001), a standardized test, was used to assess children's letter-word recognition skills. In this task, children were shown text of increasingly complex letters and words and asked to recognize or identify them. Again, the $\mathrm{W}$ score was used in all analyses, which has a test standardization sample mean of 327.23 for a child 
Table 2. Correlation matrix for student level variables.

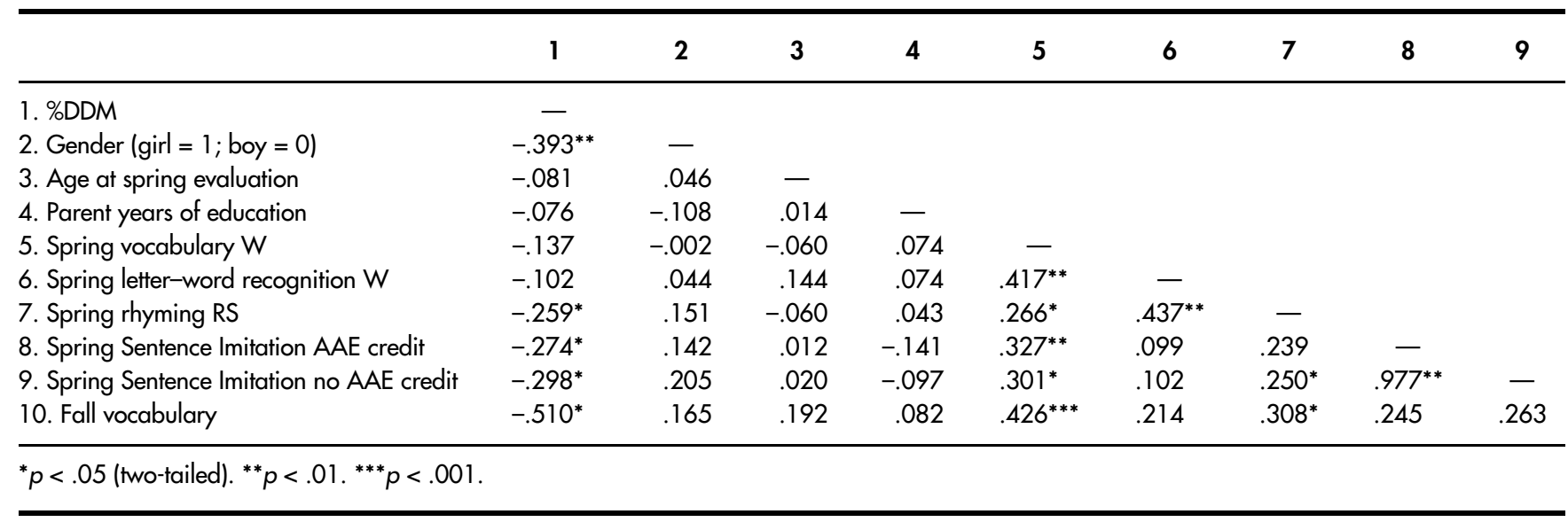

4 years of age and $354(S D=34.2, S E M=4.12)$ for a child 5 years of age, with a median reliability of .98 (McGrew et al., 1991; Woodcock \& Mather, 2001).

Spring rhyming. The Rhyming Task, a part of the state-provided literacy progress profile (Michigan Literacy Progress Profile [MLPP]; Michigan Department of Education Early Literacy Committee, 2003) was administered in the spring following procedures outlined in the MLPP manual, with one difference. The first part of the task required children to say whether two target words rhymed or not. To control for guessing, the raw score above chance (raw score minus 4 ) was used. The second part of the task was a rhyming task. Children were instructed to "tell me a word that rhymes with _.." The full raw score from this part of the task was used. The highest score a child could receive was 12 .

The relations among these language and literacy scores followed patterns typically observed for preschool children (see Table 2, top). Children with higher fall and spring vocabulary scores tended to demonstrate stronger letter-word recognition, rhyming, and sentence imitation scores than did children with lower vocabulary scores. Children with higher rhyming scores also tended to show higher letter-word recognition and sentence imitation scores than did children with lower rhyming scores. There was no significant correlation between letter-word recognition and sentence imitation scores. Note also that children in the urban fringe district started the preschool year with significantly lower fall vocabulary scores than did children in the midsized city, $t(52)=2.47, p=.01$. Overall, children began the preschool year varying widely in their fall vocabulary raw scores (see Table 1), ranging from 23 to 56. Children's standard score on the spring letter-word recognition measure was $105(S D=14.5$, mean test sample $=100$, $S D=15)$ but standard scores varied widely, from 69 (more than $2 S D$ s below expectations) to 141 (well above average). Standard scores on the spring vocabulary measure were also within age expectations (standard score mean $=101, S D=8.6$ ) and standard scores ranged from 84 to 120 . Their scores on the TOLD-2:P Sentence Imitation subtest were about 6 months below age expectations, on average, when credit was given for AAE use. Scores were 9 months below expectations when no credit for AAE use was provided (see Table 1).

\section{Parent Education}

Parent education levels were determined based on self-report from a parent questionnaire administered as part of the larger project (Connor, 2002). Approximately $7 \%$ of the parents did not complete questionnaires. Missing data analyses indicated that outcomes and predictors for students whose parents returned the questionnaire were not significantly different than for students whose parents did not return the questionnaire. Home visits were conducted for a self-selected sample of families $(n=10)$. Transcripts revealed that all parents and children used features of AAE during their informal conversations at home, including children who used very few or no features of AAE during the oral narrative using the wordless storybook prompt.

\section{$\overline{\text { Results }}$ \\ Analytic Strategies}

Hierarchical linear modeling (HLM; Raudenbush \& Bryk, 2002) was used to examine the effect of percent DDM on children's emergent reading skills and to control for the nested nature of the data, children nested in classrooms. Descriptive statistics for HLM are provided in Table 1 . Because between 1 and 16 children were in each of 10 classrooms (median $=4.5$, total $n=63$ ), some of the variance in outcomes might be explained by their shared experience (i.e., a classroom effect). HLM enables a partitioning of child and classroom variance, 
which permits better estimation of standard errors (Raudenbush \& Bryk, 2002). Additionally, visual inspection of the data revealed that the relation between outcomes and percent DDM might be nonlinear, which can be tested using HLM by entering a quadratic term (percent DDM squared) along with a linear term (percent DDM). Child variables were entered at Level 1 and classroom variables at Level 2 . All continuous variables were centered at their grand mean.

Missing data (i.e., fall vocabulary and parent education) were accommodated by replacing the mean of the variable for the missing data point and then creating a new variable wherein cases with missing values were coded 1 and all other cases 0 . In this way, the fitted value of the missing variable was considered in the analyses.

As discussed previously, a number of known child characteristics are related to students' AAE use and their literacy development, including age, gender, and SES. We controlled for fall vocabulary to take into account individual differences among children's vocabulary as they began preschool. Additionally, the sample was drawn from two school districts in communities that differed in racial make-up, which may also be related to dialect use (Wolfram et al., 1999). A significantly higher proportion of the children in the urban-fringe classrooms were African American (see Table 1) compared to the midsized city classrooms. There was a trend that African American children in the urban-fringe district generally used AAE more frequently than did children in the midsized city district (see Table 1), although differences did not reach levels of significance. Children in the urban-fringe district did demonstrate significantly lower fall vocabulary skills than did children in the midsized city.

Of the child variables, children's fall vocabulary and gender were systematically related to AAE use. Children with higher fall vocabulary scores tended to use $\mathrm{AAE}$ with less frequency than did children with lower fall vocabulary scores $(r=-.51, p<.001)$. Boys used AAE significantly more frequently than did girls (boys mean $=4.63$, girls mean $=2.50), t(61)=-3.34, p=.001$. None of the other child and classroom variables were significantly associated with their AAE use (see Table 2). Surprisingly, caregiver education, a proxy for SES, was not related to AAE use (mean difference for no college versus college $=.167), t(55)=.170, p=.86$. This may have been because all of the preschoolers participating in this study met entrance criteria for Head Start and the state readiness program, which are based, in large part, on family income levels.

Failing to include child, home, and classroom variables in our models might bias the results regarding the relation between $\mathrm{AAE}$ and the child outcomes in the spring. Because children's fall vocabulary contributed to all but one of the outcomes (letter-word recognition), it was included in all of the models. Each remaining variable was tested and any failing to contribute significantly to the outcomes was trimmed to create more parsimonious models. An exemplar model is provided in Appendix C.

\section{Relation of AAE Use and Spring Outcomes}

The results of HLM revealed that, overall, children who used AAE forms either very frequently (higher percent DDM) or very infrequently (lower percent DDM) demonstrated stronger spring rhyming, sentence imitation, and letter-word recognition skills than did children who used AAE forms with moderate frequency (see Tables $3-6)$. The linear $\left(\gamma_{20}\right.$, percent DDM) and/or quadratic $\left(\gamma_{30}\right.$, percent DDM squared) trends for percent DDM were significantly related to children's spring rhyming, sentence imitation, and letter-word scores. As Figures 1-3 confirm, there was a U-shaped relation between percent DDM and children's spring rhyming, sentence imitation (with and without AAE credit), and letter-word recognition. Keep in mind that the outcome and DDM variables are continuous and that children were not examined by DDM group. The graphs represent fitted trajectories.

There was no systematic relation, either linear or quadratic, between spring vocabulary and preschoolers' AAE use (see Table 7). Indeed, only fall vocabulary

Table 3. HLM results for AAE and spring letter-word recognition.

\begin{tabular}{|c|c|c|c|c|}
\hline Fixed effect & Coefficient & SE & $t(d f)$ & $p$ \\
\hline \multicolumn{5}{|l|}{ For $\beta_{0}$ (intercept) } \\
\hline Intercept $\gamma_{00}$ & 339.92 & 4.76 & $74.23(9)$ & $<.001$ \\
\hline \multicolumn{5}{|c|}{ For $\beta_{1}$ fall vocabulary } \\
\hline$\gamma_{10}$ & .82 & .45 & $1.82(58)$ & .07 \\
\hline \multicolumn{5}{|l|}{$\begin{array}{l}\text { For } \beta_{2} \text { missing fall } \\
\text { vocabulary }\end{array}$} \\
\hline$\gamma_{20}$ & -11.60 & 8.45 & $-1.37(58)$ & .17 \\
\hline \multicolumn{5}{|l|}{ For $\% \mathrm{DDM} \beta_{3}$} \\
\hline$\gamma_{30}$ & -.90 & 1.33 & $-0.67(58)$ & .50 \\
\hline \multicolumn{5}{|c|}{$\begin{array}{l}\text { For \%DDM quadratic } \\
\quad \text { trend } \beta_{4}\end{array}$} \\
\hline$\gamma_{40}$ & .85 & .33 & $1.92(58)$ & .05 \\
\hline Random effect & & Variance & $\chi^{2}(d f)$ & \\
\hline $\begin{array}{l}\text { Intercept } \\
\text { Level } 1\end{array}$ & $\begin{array}{l}\text { UO } \\
R\end{array}$ & $\begin{array}{r}.12 \\
547.61\end{array}$ & $7.50(9)$ & $>.50$ \\
\hline
\end{tabular}

Note. All variables are centered at their grand mean for this sample except for missing fall vocabulary, where missing $=1$, all others $=0$. 
Table 4. HLM results for AAE and spring phonological awareness (rhyming).

\begin{tabular}{|c|c|c|c|c|}
\hline Fixed effect & Coefficient & SE & $t(d f)$ & $p$ \\
\hline \multicolumn{5}{|l|}{ For $\beta_{0}$ (intercept) } \\
\hline Intercept $\gamma_{00}$ & 3.57 & 1.12 & $3.09(9)$ & .001 \\
\hline \multicolumn{5}{|c|}{ For $\beta_{1}$ fall vocabulary } \\
\hline$\gamma_{10}$ & .17 & .08 & $2.14(58)$ & .04 \\
\hline \multicolumn{5}{|l|}{$\begin{array}{l}\text { For } \beta_{2} \text { missing fall } \\
\text { vocabulary }\end{array}$} \\
\hline$\gamma_{20}$ & -2.14 & 1.46 & $-1.47(58)$ & .14 \\
\hline \multicolumn{5}{|l|}{ For $\% D D M \beta_{3}$} \\
\hline$\gamma_{30}$ & -.52 & .22 & $-2.26(58)$ & .02 \\
\hline \multicolumn{5}{|c|}{$\begin{array}{l}\text { For } \% \mathrm{DDM} \text { quadratic } \\
\quad \text { trend } \beta_{4}\end{array}$} \\
\hline$\gamma_{40}$ & .24 & .08 & $3.11(58)$ & .003 \\
\hline Random effect & & Variance & $\chi^{2}(d f)$ & \\
\hline Intercept & UO & .005 & $9.76(9)$ & .36 \\
\hline Level 1 & $\mathrm{R}$ & 16.13 & & \\
\hline
\end{tabular}

Note. All variables are centered at their grand mean for this sample except for missing fall vocabulary, where missing $=1$, all others $=0$.

significantly predicted spring vocabulary. On average, for every point higher children scored for fall vocabulary, their spring vocabulary score increased more than half a point.

Children with higher fall vocabulary scores also achieved significantly stronger spring rhyming, sentence imitation, and letter-word scores, on average, than did children with lower fall scores. Children living in the urban-fringe district tended to score about 2 points higher on sentence imitation (without AAE credit) than did children living in the midsized city. District attended had no systematic effect on the other child outcomes.

\section{Children's Use of AAE}

Twenty-seven percent of children used at least one feature of AAE on the Sentence Imitation subtest, where expectations for SAE were explicit, whereas $87 \%$ of children used AAE during their oral narrative elicited using a wordless storybook, where expectations for SAE were more implicit. Of the 7 children who used the most AAE during the wordless storybook task (DDM > 7\%) and achieved scores above 5 on the Sentence Imitation subtest, 4 used no features of AAE on the Sentence Imitation subtest, 1 used one feature, 1 used two features, and 1 used four features. That is, their AAE use was sensitive to context, suggesting that they were able to code-shift.
Table 5. HLM results for AAE and spring sentence imitation with no credit for AAE.

\begin{tabular}{|c|c|c|c|c|}
\hline Fixed effect & Coefficient & SE & $t(d f)$ & $p$ \\
\hline \multicolumn{5}{|l|}{ For $\beta_{0}$ (intercept) } \\
\hline Intercept $\gamma_{00}$ & 3.07 & .94 & $3.25(8)$ & .01 \\
\hline District $\gamma_{01}$ & 1.89 & .99 & $1.90(8)$ & .09 \\
\hline \multicolumn{5}{|c|}{ For $\beta_{1}$ fall vocabulary } \\
\hline$\gamma_{10}$ & .14 & .07 & $2.00(57)$ & .05 \\
\hline \multicolumn{5}{|l|}{$\begin{array}{l}\text { For } \beta_{2} \text { missing fall } \\
\text { vocabulary }\end{array}$} \\
\hline$\gamma_{20}$ & -.20 & 1.26 & $-0.16(57)$ & .87 \\
\hline \multicolumn{5}{|l|}{ For $\% D D M \beta_{3}$} \\
\hline$\gamma_{30}$ & -.63 & .19 & $-3.22(57)$ & .003 \\
\hline \multicolumn{5}{|c|}{$\begin{array}{l}\text { For \%DDM quadratic } \\
\quad \text { trend } \beta_{4}\end{array}$} \\
\hline$\gamma_{40}$ & .23 & .06 & $3.16(57)$ & .001 \\
\hline Random effect & & Variance & $\chi^{2}(d f)$ & \\
\hline Intercept & UO & .002 & $6.787(8)$ & $>.500$ \\
\hline Level 1 & $\mathrm{R}$ & 11.62 & & \\
\hline
\end{tabular}

Note. All variables are centered at their grand mean for this sample except for missing fall vocabulary, where missing $=1$, all others $=0$.

\section{Children's AAE Use in the Oral Narrative Elicitation-Implicit Expectation for SAE}

Fifty-five of the children in this study used morphosyntactic AAE forms during their oral narrative elicitation; only 8 did not. A coded transcript is provided in Appendix B. Children who used AAE features more and less frequently were distributed fairly evenly among the classrooms and there was more variability among the children within classrooms than between classrooms (percent DDM between-classroom variance, $\mathrm{u}_{0}=.002$, $\chi^{2}[9]=6.47, p>.5$; percent $\mathrm{DDM}$ within-classroom variance, $r=7.41$ ). Also, frequency and types of AAE features used among the children were highly variable. The distribution of $\mathrm{AAE}$ types during the oral narrative elicitation is provided in Appendix D.

Percent DDM ranged from 0 to 8.9, with a mean percent DDM of $3.51(S D=2.72)$; on average, about one out of five of the children's utterances incorporated an AAE morphosyntactic form. Approximately $13 \%$ of the children used no AAE features at all during the oral narrative elicitation; $43 \%$ had percent DDMs of less than 3 (cumulative percent $=50$ ); an additional $25 \%$ had percent DDMs falling between 3 and 5.5; the remaining $25 \%$ of the children had DDMs falling between 6.10 and 8.90. Of the $22 \mathrm{AAE}$ morphosyntactic features coded, 18 were observed to be used at least once. Zero 
Table 6. HLM results for AAE and spring sentence imitation with credit for AAE.

\begin{tabular}{|c|c|c|c|c|}
\hline Fixed effect & Coefficient & SE & $t(d f)$ & $p$ \\
\hline \multicolumn{5}{|l|}{ For $\beta_{0}$ (intercept) } \\
\hline Intercept $\gamma_{00}$ & 3.23 & 1.01 & $3.20(8)$ & .01 \\
\hline District $\gamma_{01}$ & 2.15 & 1.06 & $2.03(8)$ & .07 \\
\hline \multicolumn{5}{|c|}{ For $\beta_{1}$ fall vocabulary } \\
\hline$\gamma_{10}$ & .15 & .07 & $2.07(57)$ & .04 \\
\hline \multicolumn{5}{|l|}{$\begin{array}{l}\text { For } \beta_{2} \text { missing fall } \\
\text { vocabulary }\end{array}$} \\
\hline$\gamma_{20}$ & -.45 & 1.34 & $-0.33(57)$ & .74 \\
\hline \multicolumn{5}{|l|}{ For $\% D D M \beta_{3}$} \\
\hline$\gamma_{30}$ & -.64 & .21 & $-3.11(57)$ & .003 \\
\hline \multicolumn{5}{|c|}{$\begin{array}{l}\text { For } \% \mathrm{DDM} \text { quadratic } \\
\quad \text { trend } \beta_{4}\end{array}$} \\
\hline$\gamma_{40}$ & .26 & .07 & $3.82(57)$ & $>.001$ \\
\hline Random effect & & Variance & $\chi^{2}(d f)$ & \\
\hline Intercept & UO & .003 & $6.659(8)$ & $>.500$ \\
\hline Level 1 & $\mathrm{R}$ & 13.19 & & \\
\hline
\end{tabular}

Note. All variables are centered at their grand mean for this sample except for missing fall vocabulary, where missing $=1$, all others $=0$.

copula/auxiliary, optional subject-verb agreement, and zero past tense were used most frequently and by the greatest proportion of the children (see Appendixes A and D).

\section{AAE Use on the Sentence Imitation Subtest-Explicit Expectation for AAE}

In contrast to the oral narrative elicitation, fully $73 \%$ of children (46 in all) did not use any $\mathrm{AAE}$ features

Figure 1. Relation between children's AAE use (percent DDM) and phonological awareness (rhyming) raw score. Graph created using HLM version 6.02.

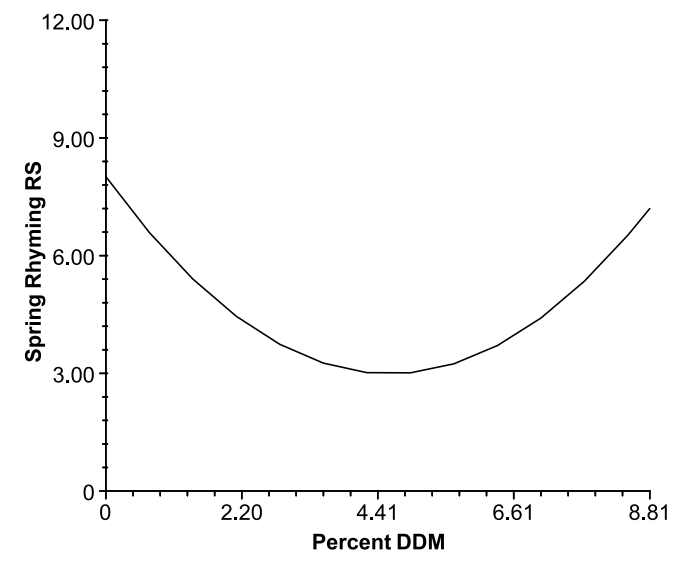

Figure 2. Relation between children's AAE use (percent DDM) and Sentence Imitation raw score with no credit for AAE tokens (top) and with credit given for AAE tokens (bottom). The circled portion of the fitted curve (top figure) indicates children who may be dialect shifting across contexts, using high amounts of AAE on the oral narrative elicitation using a wordless storybook but low amounts during sentence imitation. Graph created using HLM version 6.02.
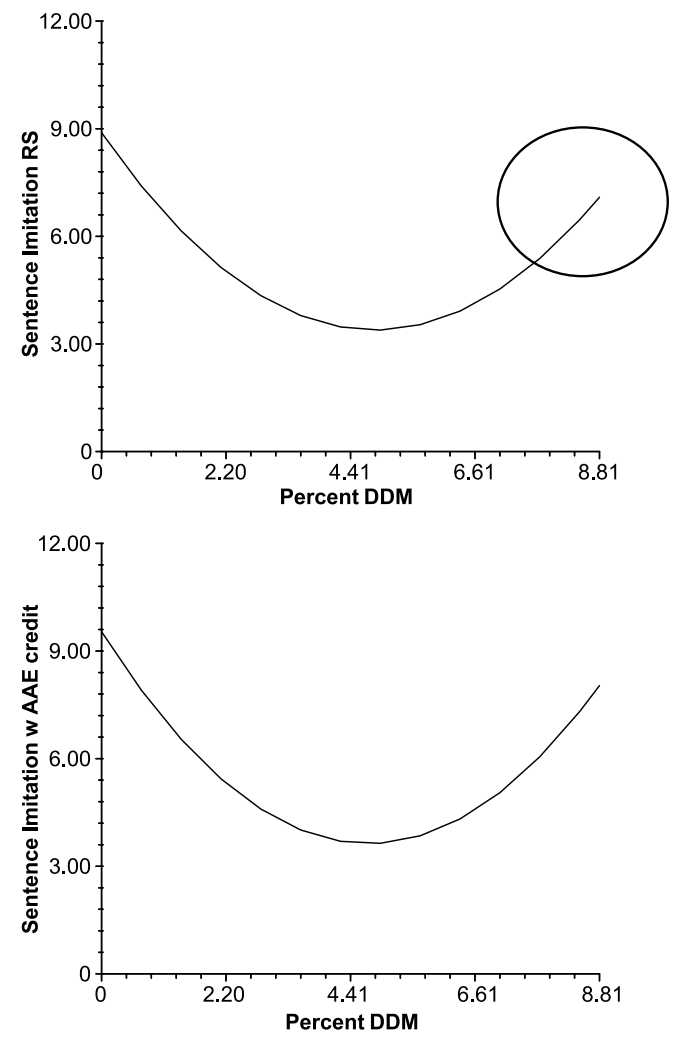

when repeating the target sentences on the sentence imitation task. Of the remaining 27\%, 7 children used AAE in one of the target sentences, an additional 6 children used AAE in two target sentences, and 4 of the children used AAE in either 3 or 4 of the target sentences. This non-normal distribution precluded statistical analyses, including statistical comparison of AAE across contexts.

On the Sentence Imitation subtest, on average, the raw score for all children, when credit was given for $\mathrm{AAE}$ feature production, was significantly higher than the raw score when no credit was given (mean difference $=$ $.51), t(62)=4.18, p<.001$. Both scores were below age expectations (see Table 1 ).

On this subtest, AAE forms used were restricted to four types across 8 target sentences. Children most frequently substituted AAE features for SAE features in the target sentences "Her friends walk(ed) to school" (zero past tense), "After the party, the boy(s) fixed the car" (zero plural) or "After the party the boys fix(ed) the car" (zero past tense), and "Although we (are) happy, we 
Figure 3. Relation between children's AAE use (percent DDM) and letter-word recognition W score. Graph created using HLM version 6.02 .

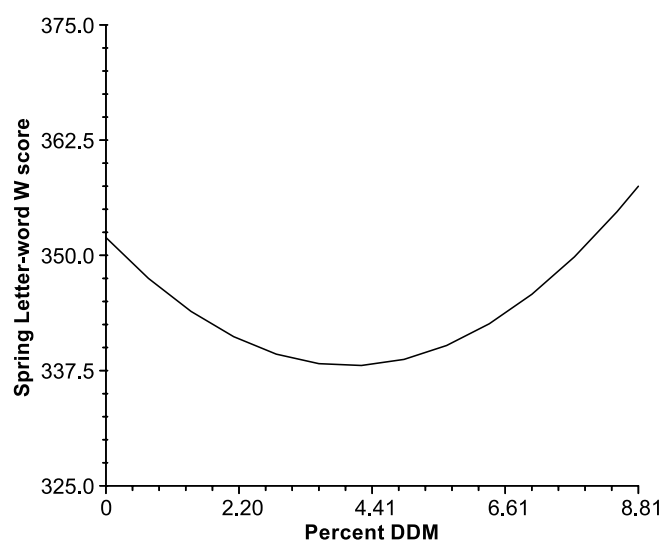

are not going to stay" (zero copula/auxiliary). The latter sentence occurred late in the test and so was presented only to students achieving high scores. The others occurred within the first six items on the test.

\section{$\overline{\text { Discussion }}$}

The purpose of this study was to examine the relation between African American preschoolers' oral language, specifically their use of AAE, and their vocabulary, metalinguistic awareness, and emergent literacy development and their AAE use across two contexts. We probed for potential oral language and literacy links by examining the relation between preschoolers' use of AAE during an oral narrative elicitation and their performance on key predictors of literacy development. We anticipated that this relation might be complex, and this was the case. Children who used AAE features more frequently or less frequently in the oral narrative elicitation with the wordless storybook demonstrated stronger emergent literacy skills overall than did children who used AAE with moderate frequency. There was a U-shaped relation (see Figures 1-3).

We hypothesized that children would be likely to use AAE similarly across contexts because they had only begun to experience formal schooling and probably had had only limited exposure to text. This was not the case. Fully $87 \%$ of children used a feature of AAE at least once in the oral narrative elicitation but only $27 \%$ used AAE features in the sentence imitation task. This suggests that, even in preschool, students may be responding to different expectations for $\mathrm{AAE}$ and SAE use across contexts. They appeared to decrease their use of AAE (and increased use of SAE by implication) as the expectations for school and book forms of SAE increased.
Table 7. HLM results for AAE and spring vocabulary.

\begin{tabular}{|c|c|c|c|c|}
\hline Fixed effect & Coefficient & SE & $t(d f)$ & $p$ \\
\hline \multicolumn{5}{|l|}{ For $\beta_{0}$ (intercept) } \\
\hline Intercept $\gamma_{00}$ & 464.75 & 1.42 & $325.28(9)$ & $<.001$ \\
\hline \multicolumn{5}{|c|}{ For $\beta_{1}$ fall vocabulary } \\
\hline$\gamma_{10}$ & .56 & .14 & $4.00(58)$ & $<.001$ \\
\hline \multicolumn{5}{|l|}{$\begin{array}{l}\text { For } \beta_{2} \text { missing fall } \\
\text { vocabulary }\end{array}$} \\
\hline$\gamma_{20}$ & -2.09 & 2.63 & $-0.79(58)$ & .42 \\
\hline \multicolumn{5}{|l|}{ For $\% \mathrm{DDM} \beta_{3}$} \\
\hline$\gamma_{30}$ & -.006 & .41 & $-0.01(58)$ & .98 \\
\hline \multicolumn{5}{|c|}{$\begin{array}{l}\text { For \%DDM quadratic } \\
\quad \text { trend } \beta_{4}\end{array}$} \\
\hline$\gamma_{40}$ & .25 & .13 & $1.84(58)$ & .07 \\
\hline Random effect & & Variance & $\chi^{2}(d f)$ & $p$ \\
\hline Intercept & UO & .01 & $9.10(9)$ & .42 \\
\hline Level 1 & $\mathrm{R}$ & 53.31 & & \\
\hline
\end{tabular}

Note. All variables are centered at their grand mean for this sample except for missing fall vocabulary, where missing $=1$, all others $=0$.

In particular, these preschoolers appeared to dialect shift between the two contexts and many used SAE features when the expectation for SAE was highly explicit, in the sentence imitation task. They were more likely to use AAE features when the expectation for SAE was implicit, during their oral narrative elicitation using a wordless storybook.

These findings extend recent findings by Craig and Washington (2004a) and Charity et al. (2004), who reported that $\mathrm{AAE}$ usage was related to literacy acquisition in important ways. They found that for elementarygrade students, less frequent use of AAE forms at first grade after the preschool/kindergarten shift from greater to less frequent AAE use (Craig \& Washington, 2004a) and greater sensitivity to SAE (Charity et al., 2004) were positively related to reading achievement. In this study, preschoolers who used AAE features less frequently demonstrated stronger literacy skills than did preschoolers who used AAE with moderate frequency. By implication, preschoolers with greater knowledge of SAE achieved stronger emergent literacy skills. At the same time, preschoolers who were proficient and prolific users of AAE were among the most linguistically adept in our sample. Preschoolers who used AAE features most frequently (and by implication used less SAE) demonstrated stronger emergent literacy skills than did students who used AAE with moderate frequency. These findings suggest that overall linguistic skill is a better predictor of students' reading than whether or not a child uses AAE. 
As we discussed, there are currently three major theories regarding why children's AAE use might have a negative impact on their developing literacy: (a) teacher perception and reduced expectations for children who are heavy users of AAE, (b) the mismatch between the SAE children encounter in text and the classroom and the AAE they speak, and (c) the ability to dialect shift, which holds that it is not AAE per se that impedes literacy development but rather insufficient knowledge of SAE and the inability to dialect shift to SAE as the context demands. The U-shaped relation between children's AAE use and their literacy skills provides evidence that the third theory, dialect awareness or shifting, may be the most tenable among the three. Teacher negative perceptions of AAE and the mismatch hypotheses would result in a negative linear relation between children's use of AAE and their literacy skills, which was not observed for the preschoolers in this study. Nor did teacher survey and classroom observations reveal teacher bias for the 5 teachers, in either their morning or afternoon class, in this study (see Appendix E).

There was no evidence for the mismatch hypothesis, which would have also predicted that students using $\mathrm{AAE}$ with greater frequency would have more difficulty learning early literacy skills than would students who used AAE features with more moderate frequencya negative linear relation. Instead, we found a significant U-shaped relation between students' AAE use and their spring phonological awareness (rhyming), sentence imitation, and letter-word recognition skills. The heaviest AAE users had more proficient phonological awareness, sentence imitation, and letter-word skills than did more moderate AAE users. Phonological awareness is one of the strongest predictors of later reading success (Bryant, Maclean, \& Bradley, 1990; Catts, 1993; Vellutino et al., 1996) and a skill frequently cited when explaining the potential causal mechanisms of the mismatch hypothesis (see, for example, Charity et al., 2004). Sentence imitation is a key kindergarten predictor of later literacy skills (Catts et al., 2001) and children who begin school with greater letter knowledge typically demonstrate stronger reading skills later on (Bond \& Dykstra, 1967; Catts et al., 2001). There was no relation between spring vocabulary and AAE use, although vocabulary is one of the most powerful predictors of later academic success (Connor, Son, Hindman, \& Morrison, 2005; NICHDECCRN, 2005).

The distinctive $\mathrm{U}$-shaped relation between preschoolers' AAE use and their metalinguistic awareness, vocabulary, and emergent literacy skills coupled with evidence that many children are switching between SAE and AAE in different contexts offers support for the dialect shifting and dialect awareness hypotheses (Charity et al., 2004; Craig \& Washington, 2004a). Perhaps the most compelling evidence that some preschoolers are dialect shifting is seen when we examine Figure 2 more closely. Students who used AAE with the greatest frequency on the oral narrative elicitation generally demonstrated age-appropriate performance on the Sentence Imitation subtest (students falling within the circle in Figure 2). These children, by implication, demonstrated their knowledge of SAE (Charity et al., 2004) even though they did not use SAE as frequently in their oral narrative elicited using the wordless story book. These children were dialect shifting, perhaps in response to explicit expectations for SAE on the Sentence Imitation subtest.

The observed dialect shifting across the two contexts may represent an emerging pragmatic awareness (a metalinguistic skill) that the language used at home may not be the language expected at school (see also Craig \& Washington, 2004a). Supporting this supposition, children's frequency of AAE feature use demonstrated a stronger relation with the two metalinguistic measures, phonological awareness (rhyming) and morphosyntactic awareness (sentence imitation), than with their spring vocabulary skills.

Many preschoolers did not respond to the implicit expectation for SAE in the oral narrative elicitation, even those with strong language, phonological awareness, and emergent literacy skills. This may be because preschool is a time of transition between home and school. Thus, dialect shifting might be an emerging skill and the $U$-shaped relation provides evidence of this. Some of the linguistically adept children were not yet responsive to more subtle cues for SAE. For older schoolaged children, the $\mathrm{U}$-shaped relation may not be in evidence. We might assume that, after gaining more school experience, linguistically able children will dialect shift, leaving the preschoolers who used AAE moderately in this sample among high AAE users in older samples. This mechanism would yield the negative linear relation observed in Craig and Washington (2004a) and Charity et al. (2004). To test this hypothesis, longitudinal studies with larger samples are needed.

Explicit instruction in dialect awareness (i.e., the conscious awareness of code shifting) for African American children who might not be sensitive to subtle and implicit cues may contribute to stronger literacy outcomes. As demonstrated with phonological awareness (Bryant et al., 1990; Bus \& van IJzendoorn, 1999; Castles \& Coltheart, 2004; Torgesen et al., 2001), metalinguistic awareness skills can be taught successfully and when taught yield stronger literacy outcomes. Perry and Delpit (1998), for example, provided descriptions of appropriate instructional strategies that may be effective and culturally sensitive (Delpit, 2002). However, we cannot claim a causal relation between dialect awareness/ shifting and literacy development. This was a correlational study and so the causal mechanisms underlying the U-shaped relation between preschoolers' AAE and 
literacy remain unclear. What is needed are rigorous intervention studies with students randomly assigned to treatment and control groups where treatment group students receive explicit instruction in dialect shifting.

AAE feature types, frequency, and distribution among these preschoolers were highly similar to those observed in studies with other samples of preschool age children (e.g., Craig \& Washington, 2002; Jackson \& Roberts, 2001). Also, as found in these studies, children's AAE use was highly variable both among children and across contexts. These findings contribute to the extant literature that has found that AAE is not a homogeneous construct, but rather is highly heterogeneous, and thus broad assumptions regarding its use are probably not appropriate in either research or educational settings.

The findings, as a whole, underscore the importance of considering complex relations within data sets. Had we tested only the linear relation and not considered the quadratic trend, we would have found a negative correlation for two of the outcomes - rhyming and sentence imitation (see Table 2). It would have appeared that children with stronger language and metalinguistic skills would, on average, use features of AAE less frequently. Instead, we found that children who were productive and prolific users of AAE were among the most linguistically adept in our sample.

In summary, the results of this study revealed that African American preschoolers' AAE use in and of itself is probably not contributing significantly to the BlackWhite achievement gap. In fact, for many children, heavy $\mathrm{AAE}$ use in preschool appears to be related to greater linguistic flexibility and metalinguistic awareness, which would place these children at less risk for later reading difficulties than students who use AAE more moderately. Further, linguistically proficient African American students may begin to dialect shift as soon as they begin their formal schooling career. Dialect shifting appears to be strongly associated with other metalinguistic skills, and the ability to shift dialects across contexts may be indicative of emerging pragmatic awareness. We are learning more about the efficacy of explicit instruction in preschool. If indeed children's ability to dialect shift is causally associated with stronger literacy development, then the efficacy of explicit instruction in switching between $\mathrm{AAE}$ and SAE deserves rigorous investigation as a strategy toward enhancing African American students' academic proficiency and alleviating the achievement gap.

\section{Acknowledgments}

This study was funded, in part, by the Spencer Foundation and the Center for Improvement of Early Reading Achievement, U.S. Department of Education. We would like to first recognize the contribution of Stephen Raudenbush, University of Michigan, to this study and to thank him for his help with the analyses. Our thanks go to the members of the Florida State University writing group and Howard Goldstein for their thoughtful suggestions on the final draft of this manuscript. We also thank the families, teachers, and school personnel, without whom this study would not have been possible. This study used data collected as part of the first author's dissertation submitted to the School of Education, University of Michigan in partial fulfillment of her doctoral degree.

\section{References}

Artiles, A. J., \& Zamora-Duran, G. (1997). Disproportional representation: A contentious and unresolved predicament. In A. J. Artiles \& G. Zamora-Duran (Eds.), Reducing disproportionate representation of culturally diverse students in special and gifted education (pp. 1-6). Reston, VA: Council for Exceptional Children.

Ball, A. F. (1992). Cultural preference and the expository writing of African-American adolescents. Written Communication, 9, 501-532.

Balow, I. H., Farr, R. C., \& Hogan, T. R. (1992). Metropolitan Achievement Tests (7th ed.). San Antonio, TX: The Psychological Corporation.

Baratz, J. C. (1969). A bidialectal task for determining language proficiency in economically disadvantaged Negro children. Child Development, 40, 889-901.

Barnett, S. W. (1995). Long-term effects of early childhood programs on cognitive and school outcomes. Future of Children, 5(3), 25-50.

Berman, R. A., \& Slobin, D. I. (1994). Relating events in narrative: A crosslinguistic developmental study. Hillsdale, NJ: Erlbaum.

Bond, G. L., \& Dykstra, R. (1967). The cooperative research program in first-grade reading instruction. Reading Research Quarterly, 2(4), 5-142.

Bronfenbrenner, U. (1986). Ecology of the family as a context for human development: Research perspectives. Developmental Psychology, 22, 723-742.

Brooks-Gunn, J., Duncan, G. J., Klebanov, P. K., \& Sealand, N. (1993). Do neighborhoods influence child and adolescent development? American Journal of Sociology, 99, 353-395.

Brown, A. (Ed.). (1980). The Ann Arbor Black English case. Gainseville, FL: John Dewey Society.

Bryant, P., Maclean, M., \& Bradley, L. (1990). Rhyme, language, and children's reading. Applied Psycholinguistics, 11, 237-252.

Bus, A. G., \& van IJzendoorn, M. H. (1999). Phonological awareness and early reading: A meta-analysis of experimental training studies. Journal of Educational Psychology, 91, 403-414.

Castles, A., \& Coltheart, M. (2004). Is there a causal link from phonological awareness to success in learning to read? Cognition, 91, 77-111.

Catts, H. W. (1993). The relationship between speechlanguage impairments and reading disabilities. Journal of Speech and Hearing Research, 36, 948-958.

Catts, H. W., Fey, M., Zhang, X., \& Tomblin, B. (1999). Language basis of reading and reading disabilities: 
Evidence from a longitudinal investigation. Scientific Studies of Reading, 3, 331-361.

Catts, H. W., Fey, M. E., Zhang, X., \& Tomblin, J. B. (2001). Estimating the risk of future reading difficulties in kindergarten children: A research-based model and its clinical implementation. Language, Speech, and Hearing Services in Schools, 32, 38-50.

Cecil, N. L. (1988). Black dialect and academic success: A study of teacher expectations. Reading Improvement, 25(1), 34-38.

Charity, A. H., Scarborough, H. S., \& Griffin, D. (2004). Familiarity with "School English" in African-American children and its relation to early reading achievement. Child Development, 75, 1340-1356.

Connor, C. M. (2002). Preschool children and teachers talking together: The influence of child, family, teacher, and classroom characteristics on children's developing literacy. Doctoral Dissertation, University of Michigan, Ann Arbor.

Connor, C. M., Son, S., Hindman, A., \& Morrison, F. J. (2005). Teacher qualifications, classroom practices, family characteristics and preschool experience: Complex effects on first graders' vocabulary and early reading outcomes. Journal of School Psychology, 43, 343-375.

Cox, B. E., Fang, Z., \& Otto, B. W. (1997). Preschoolers' developing ownership of the literate register. Reading Research Quarterly, 32(1), 34-53.

Craig, H. K., Connor, C. M., \& Washington, J. A. (2003). Early positive predictors of later reading comprehension for African American students: A preliminary examination. Language, Speech, and Hearing Services in Schools, 34, 31-43.

Craig, H. K., Thompson, C. A., Washington, J. A., \& Potter, S. L. (2003). Phonological features of child African American English. Journal of Speech, Language, and Hearing Research, 46, 623-635.

Craig, H. K., \& Washington, J. A. (1994). The complex syntax skills of poor, urban, African-American preschoolers at school entry. Language, Speech, and Hearing Services in Schools, 25, 181-190.

Craig, H., \& Washington, J. (1995). African-American English and linguistic complexity in preschool discourse: A second look. Language, Speech, and Hearing Services in Schools, 26, 87-93.

Craig, H. K., \& Washington, J. A. (2002). Normative expectations for 4- to 6-year-old African American children on traditional types of language assessment tasks. American Journal of Speech Language Pathology, 11, 59-70.

Craig, H. K., \& Washington, J. A. (2004a). Grade-related changes in the production of African American English. Journal of Speech, Language, and Hearing Research, 47, $450-463$.

Craig, H. K., \& Washington, J. A. (2004b). Language variation and literacy learning. In C. A. Stone, B. J. Ehren, E. R. Silliman, \& K. Apel (Eds.), Handbook of language and literacy: Development and disorders (pp. 228-247). New York: Guilford Press.

Craig, H. K., \& Washington, J. A. (2006). Malik goes to school: Examining the language skills of African American students from preschool-5th grade. Mahwah, NJ: Erlbaum.

Craig, H. K., Washington, J. A., \& Connor, C. M. (2000, November-December). Similarities and differences in language production of African American children among reading, writing, and oracy contexts. Paper presented at the National Reading Conference Annual Meeting, Scottsdale, AZ.

Craig, H. K., Washington, J. A., \& Thompson-Porter, C. (1998). Performances of young African American children on two comprehension tasks. Journal of Speech, Language, and Hearing Research, 41, 445-457.

Darling-Hammond, L. (1997). The right to learn: A blueprint for creating schools that work. San Francisco: Josse-Bass.

Delpit, L. (2002). No kinda sense. In L. Delpit \& J. K. Dowdy (Eds.), The skin that we speak: Thoughts on language and culture in the classroom (pp. 31-48). New York: The New Press.

Dunn, L. M., \& Dunn, L. M. (1997). Peabody Picture Vocabulary Test-Third Edition. Circle Pines, MN: American Guidance Service.

Elster, C. (1994). Patterns within preschoolers' emergent readings. Reading Research Quarterly, 29, 402-418.

Fazio, B. B., Naremore, R. C., \& Connell, P. J. (1996). Tracking children from poverty at risk for specific language impairment: A 3-year longitudinal study. Journal of Speech and Hearing Research, 39, 661-624.

Federal Interagency Forum on Child and Family Statistics. (2003). America's children: Key national indicators of well being. Washington, DC: U.S. Government Printing Office.

Gemake, J. S. (1981). Interference of certain dialect elements with reading. Reading Improvement, 18(2), 183-189.

Goodman, K. S., \& Buck, C. (1973). Dialect barriers to reading comprehension revisited. Reading Teacher, 27(1), 6-12.

Harber, J. R. (1977). Influence of presentation dialect and orthographic form on reading performance of Black innercity children. Educational Research Quarterly, 2(2), 9-16.

Harber, J. R. (1982). Accepting dialect renderings of extant material on Black English-speaking children's oral reading scores. Education and Treatment of Children, 5, 271-282.

Harms, T., Clifford, R. M., \& Cryer, D. (1998). Early Childhood Environment Rating Scale (Rev. ed.). New York: Teachers College Press.

Hart, J. T., Guthrie, H. T., \& Winfield, L. (1980). Black English phonology and learning to read. Journal of Educational Psychology, 72, 636-646.

Haycock, K., Jerald, C., \& Huang, S. (2001). Closing the gap: Done in a decade. Washington, DC: Education Trust, Thinking $\mathrm{K}-16$.

Hoffman, K., \& Llagas, C. (2003, September). Status and trends in the education of Blacks (NCES 2003-034). Washington, DC: U.S. Department of Education, National Center for Education Statistics.

Horton-Ikard, R., \& Miller, J. F. (2004). It is not just the poor kids: The use of AAE forms by African-American school-aged children from middle SES communities. Journal of Communication Disorders, 37, 467-487.

Isaacs, G. J. (1996). Persistence of non-standard dialect in school-age children. Journal of Speech, Language, and Hearing Research, 39, 434-441.

Jackson, S. C., \& Roberts, J. E. (2001). Complex syntax production of African American preschoolers. Journal of Speech, Language, and Hearing Research, 44, 1083-1096. 
Jencks, C., \& Phillips, M. (1998). The Black-White test score gap. Washington, DC: Brookings Institution.

Kaufman, A., \& Kaufman, N. (1983). Kaufman Assessment Battery for Children: Interpretive manual. Circle Pines, MN: American Guidance Service.

Labov, W. (1995). Can reading failure be reversed? A linguistic approach to the question. In V. Gadsden \& D. Wagner (Eds.), Literacy among African American youth: Issues in learning, teaching, and schooling (pp. 39-68). Cresskill, NJ: Hampton.

Loban, W. (1976). Language development: Kindergarten through grade twelve. Urbana, IL: National Council of Teachers of English.

MacWhinney, B. (1994). The CHILDES project: Tools for analyzing talk (2nd ed.). Pittsburgh, PA: Carnegie Mellon University.

Manning, M. L., \& Baruth, L. G. (2003). Multicultural education of children and adolescents (3rd ed.). Boston: Allyn and Bacon.

Mayer, M. (1969). Frog, where are you? New York: Puffin Books.

McGrew, K. S., Werder, J. K., \& Woodcock, R. W. (1991). Woodcock-Johnson technical manual. Allen, TX: DLM.

Melmed, P. J. (1973). Black English phonology: The question of reading interference. In J. L. Laffey \& R. W. Shuy (Eds.), Language differences: Do they interfere? (pp. 70-85). Newark, DE: International Reading Association.

Michigan Department of Education Early Literacy Committee. (2003). Michigan Literacy Progress Profile. Retrieved September 22, 2005, from http://www.mlppmsl.net/

Morrison, F. J., Bachman, H. J., \& Connor, C. M. (2005). Improving literacy in America: Guidelines from research. New Haven, CT: Yale University Press.

National Reading Panel. (2000). Teaching children to read: An evidence-based assessment of the scientific research literature on reading and its implications for reading instruction (NIH Pub. No. 00-4769). Rockville, MD: National Institute of Child Health and Human Development.

Nelson, J. R., Benner, G. J., \& Gonzalez, J. (2003). Learner characteristics that influence treatment effectiveness of early literacy interventions: A meta-analytic review. Learning Disabilities Research and Practice, 18(4), 255-267.

Nettles, M. T., \& Perna, L. W. (1997). The African American education data book, Volume II: Preschool through high school education. Fairfax, VA: Frederick D. Patterson Research Institute.

Newcomer, P., \& Hammill, D. (1988). Test of Language Development-Second Edition: Primary. Austin, TX: Pro-Ed.

NICHD-ECCRN. (2002). Child-care structure - process outcome: Direct and indirect effects of child-care quality on young children's development. Psychological Science, 13(2), 199-206.

NICHD-ECCRN. (2004). Multiple pathways to early academic achievement. Harvard Educational Review, 74(1), $1-29$.

NICHD-ECCRN. (2005). Pathways to reading: The role of oral language in the transition to reading. Developmental Psychology, 41, 428-442.
Oetting, J. B., \& McDonald, J. L. (2001). Nonmainstream dialect use and specific language impairment. Journal of Speech and Hearing Research, 44, 207-223.

Oetting, J. B., \& McDonald, J. L. (2002). Methods for characterizing participants' nonmainstream dialect use in child language research. Journal of Speech, Language, and Hearing Research, 45, 505-518.

Ogbu, J. U. (2003). Black American students in an affluent suburb: A study of academic disengagement. Mahwah, NJ: Erlbaum.

Owings, W., \& Magliaro, S. (1998). Grade retention. Educational Leadership, 56(1), 86-88.

Perry, T., \& Delpit, L. (1998). The real Ebonics debate. Boston: Beacon.

Purcell-Gates, V., McIntyre, E., \& Freppon, P. A. (1995). Learning written storybook language in school: A comparison of low SES children in skill based and whole language classrooms. American Educational Research Journal, 32, 659-685.

Raudenbush, S. W., \& Bryk, A. S. (2002). Hierarchical linear models: Applications and data analysis methods (2nd ed.). Thousand Oaks, CA: Sage.

Rego, L. L. B., \& Bryant, P. E. (1993). The connection between phonological, syntactic and semantic skills and children's reading and spelling. European Journal of Psychology of Education, 8(3), 235-246.

Reynolds, A. J., \& Ou, S.-R. (2004). Alterable predictors of child well-being in the Chicago longitudinal study. Children and Youth Services Review, 26, 1-14.

Rystrom, R. C. (1973-1974). Perceptions of vowel lettersound relationships by first grade children. Reading Research Quarterly, 9(2), 170-185.

Scarborough, H. S. (2001). Connecting early language and literacy to later reading (dis)abilities: Evidence, theory, and practice. In S. B. Neuman \& D. K. Dickinson (Eds.), Handbook of early literacy research (pp. 97-110). New York: Guilford Press.

Senechal, M., \& LeFevre, J.-A. (2002). Parental involvement in the development of children's reading skill: A five-year longitudinal study. Child Development, 73, 445-460.

Seymour, H. N., \& Ralabate, P. K. (1985). The acquisition of a phonologic feature of Black English. Journal of Communication Disorders, 18, 139-148.

Shields, P. H. (1979). The language of poor Black children and reading performance. Journal of Negro Education, 48(2), 196-208.

Simons, H. D., \& Johnson, K. R. (1974). Black English syntax and reading interference. Research in the Teaching of English, 8, 339-358.

Snow, C. E., Burns, M. S., \& Griffin, P. (Eds.). (1998). Preventing reading difficulties in young children. Washington, DC: National Academy Press.

Standard and Poor's School Evaluation Services. (2003). Data set retrieved July 24, 2003, from http://www.ses. standardandpoors.com

Steffensen, M. S., Reynolds, R. E., McClure, E., \& Guthrie, L. F. (1982). Black English Vernacular and reading comprehension: A cloze study of third, sixth, and ninth graders. Journal of Reading Behavior, 14, 285-298. 
Stevenson, H. W., Chen, C., \& Uttal, D. H. (1990). Beliefs and achievement: A study of Black, White, and Hispanic children. Child Development, 61, 508-523.

Storch, S. A., \& Whitehurst, G. J. (2002). Oral language and code-related precursors to reading: Evidence from a longitudinal structural model. Developmental Psychology, $38,934-947$.

Sulzby, E. (1985). Children's emergent reading of favorite storybooks: A developmental study. Reading Research Quarterly, 20, 458-481.

Thompson, C. A., Craig, H. K., \& Washington, J. A. (2004). Variable production of African American English across oracy and literacy contexts. Language, Speech, and Hearing Services in Schools, 35, 269-282.

Torgesen, J. K., Alexander, A. W., Wagner, R. K., Rashotte, C. A., Voelier, K. K. S., \& Conway, T. (2001). Intensive remedial instruction for children with severe reading disabilities: Immediate and long-term outcomes from two instructional approaches. Journal of Learning Disabilities, 34(1), 33-58.

Tumner, W. E., Nesdale, A. R., \& Wright, A. D. (1987). Syntactic awareness and reading acquisition. British Journal of Developmental Psychology, 5, 25-34.

U.S. Department of Education, National Center for Education Statistics. (2003). The nation's report card: Reading highlights (No. NCES 2004-452). Washington, DC: Author.

Vellutino, F. R., Scanlon, D. M., Sipay, E. R., Small, S. G., Pratt, A., Chen, R., et al. (1996). Cognitive profiles of difficult to remediate and readily remediated poor readers: Early intervention as a vehicle for distinguishing between cognitive and experiential deficits as basic causes of specific reading disability. Journal of Educational Psychology, 88, 601-638.
Washington, J. A., \& Craig, H. K. (1998). Socioeconomic status and gender influences on children's dialectal variations. Journal of Speech, Language, and Hearing Research, 41, 1115-1124.

Washington, J. A., Craig, H. K., \& Connor, C. M. (1998, December). The oral language and reading skills of young African American children. Paper presented at the National Reading Conference, Austin, TX.

Washington, J. A., Craig, H. K., \& Kushmaul, A. J. (1998). Variable use of African American English across two language sampling contexts. Journal of Speech, Language, and Hearing Research, 41, 1115-1124.

Washington, V. M., \& Miller-Jones, D. (1989). Teacher interactions with nonstandard English speakers during reading instruction. Contemporary Educational Psychology, 14, 280-312.

Wolfram, W., Adger, C. T., \& Christian, D. (1999). Dialects in schools and communities. Mahwah, NJ: Erlbaum.

Woodcock, R. W. (1987). Woodcock Reading Mastery TestsRevised. Circle Pines, MN: American Guidance Service.

Woodcock, R. W., \& Mather, N. (2001). Woodcock-Johnson Tests of Achievement-Third Edition: Examiner's manual. Itasca, IL: Riverside.

Received May 24, 2005

Revision received September 23, 2005

Accepted November 30, 2005

DOI: 10.1044/1092-4388(2006/055)

Contact author: Carol McDonald Connor, $227 \mathrm{~N}$. Bronough, Suite 7250/FCRR, Tallahassee, FL 32312. E-mail: cconnor@fcrr.org or cconnor@fsu.edu 
Appendix A. Definitions and examples of morphosyntactic features of children's African American English.

\begin{tabular}{|c|c|}
\hline Morphosyntactic AAE feature & Example \\
\hline $\begin{array}{l}\text { Zero copula/auxiliary (COP) } \\
\text { Copula and auxiliary forms of the verb } \\
\text { to be are included variably. }\end{array}$ & $\begin{array}{l}\text { I (am) stuck in there. } \\
\text { This (is) supposed to be a frog. }\end{array}$ \\
\hline $\begin{array}{l}\text { Optional subject-verb agreement (SVA) } \\
\text { Subjects and verbs differ in number marking. }\end{array}$ & And then they was splashing the water \\
\hline $\begin{array}{l}\text { Zero past tense (PST) } \\
\text { Present forms of irregular verbs and marker -ed } \\
\text { regular verbs are used variably. }\end{array}$ & And then he said, he cover(ed) his ears \\
\hline $\begin{array}{l}\text { Undifferentiated pronoun case (UPC) } \\
\text { Pronoun case is used interchangeably. }\end{array}$ & Yesterday my aunt forgot they lunch (from sentence imitation) \\
\hline $\begin{array}{l}\text { Indefinite article (ART) } \\
\text { Regardless of vowel context, } a \text { is used instead of }\end{array}$ & He found $a(n)$ elk \\
\hline $\begin{array}{l}\text { Zero preposition (ZPR) } \\
\text { Prepositions are variably included }\end{array}$ & He called them out (of) the bushes too. \\
\hline $\begin{array}{l}\text { Appositive pronoun (PRO) } \\
\text { Two pronouns or the noun and a pronoun are } b\end{array}$ & The bees they was jumping down (also subject-verb agreement) \\
\hline $\begin{array}{l}\text { Zero to (ZTO) } \\
\text { The infinitive to is variably included. }\end{array}$ & Then he came (to) save him. \\
\hline $\begin{array}{l}\text { Existential it (EIT) } \\
\text { It is used in place of there to signify a referent. }\end{array}$ & It' is some rocks, trees, owl, \& a a tall tree and a little boy. \\
\hline $\begin{array}{l}\text { Zero -ing (ING) } \\
\text {-ing is variably used. }\end{array}$ & And they was fall(ing) in the water. \\
\hline $\begin{array}{l}\text { Zero plural (ZPL) } \\
-s \text { is used variably to mark number. }\end{array}$ & So he said, there was the two froggy(ies) that he gotta go in. \\
\hline $\begin{array}{l}\text { Zero possessive (POS) } \\
-s \text { is variably deleted or case of possessive pronc } \\
\text { possession is marked by word order. }\end{array}$ & And he called the frog('s) name \\
\hline $\begin{array}{l}\text { Fitna/sposeta/bouta (FSB) } \\
\text { Used to code imminent action }\end{array}$ & And he was bouta fall. \\
\hline $\begin{array}{l}\text { Multiple negation (NEG) } \\
\text { Clause may include two or more negatives }\end{array}$ & The frog didn't say nothing. \\
\hline $\begin{array}{l}\text { Invariant be (IBE) } \\
\text { Indicates habitual action or state }\end{array}$ & The people be helped by the king (from sentence imitation) \\
\hline $\begin{array}{l}\text { Ain't (AIN) } \\
\text { Negative auxiliary (e.g., have not) }\end{array}$ & That ain't no froggy. \\
\hline $\begin{array}{l}\text { Reqularized reflexive pronoun (REF) } \\
\text { Variable use of hisself, theyself, theirselves } \\
\text { instead of reflexive pronoun }\end{array}$ & He told hisself and his dog came here. \\
\hline
\end{tabular}

Note. Examples are from the oral narrative elicitation unless indicated. Codes used in the transcript in Appendix B are indicated with parentheses. 
Appendix B (p. 1 of 2). Exemplar transcript of an oral narrative elicitation.

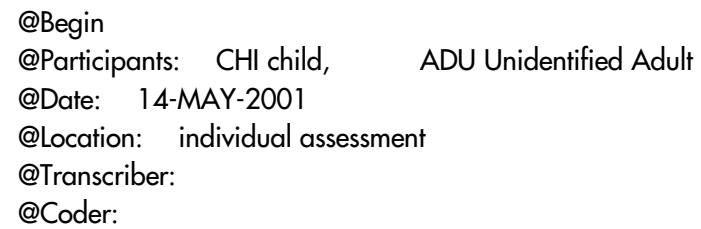


Appendix B (p. 2 of 2). Exemplar transcript of an oral narrative elicitation.

${ }^{*} \mathrm{CHI}$ and he was bouta fall.

\%AAE: $\quad$ \$FSB

${ }^{*} \mathrm{CHI}: \quad$ and they was down real-ly fast.

\%AAE: \$SVA

${ }^{*} \mathrm{CHI}$ : and then the boy was, that-' is a frog \&fr.

${ }^{*} \mathrm{CHI}: \quad$ and then him there.

\%AAE: \$UPC

${ }^{*} \mathrm{CHI}$ : and then got him.

${ }^{*} \mathrm{CHI}$ : and then they got in a \&p pond.

${ }^{*} \mathrm{CHI}: \quad<a n d$ then and then $>[/]$ and then he was happy.

${ }^{*} \mathrm{CHI}$ : then $<$ then him got> [//] he say we fine.

\%AAE: \$COP

${ }^{*} \mathrm{CHI}: \quad<a n d$ then> $[/]$ and then because $x x x$ and then he got on <his \&w> [//] his \&uh tree \&w.

${ }^{*} \mathrm{CHI}$ : and then $x x x$ out the pond.

${ }^{*} \mathrm{CHI}: \quad$ <and then> [/] and then the little boy stay \&a because he look-ing for a frog.

\%AAE: \$SVA \$COP

${ }^{*} \mathrm{CHI}: \quad$ and then he was real-ly happy < to to find frog $>[/ /]$ to $<$ find him $>[/ /]$ find frog.

*CHI: and then $<$ he he him like to> [//] him was come back $x x x$.

\%AAE: $\quad$ \$UPC

${ }^{*} \mathrm{ADU}$ :

${ }^{*} \mathrm{CHI}$ :

\%AAE:

@end

$<$ him \&uh> [/] him was <come back> [/] come back.

\$UPC

Appendix C. Exemplar hierarchical linear model.

Level 1-Child

$Y_{i j}=\beta_{0 j}+\beta_{1}\left(\right.$ fall vocabulary $_{i j}+\beta_{2 i}(\text { percent DDM })_{i j}+\beta_{3 i}(\text { percent DDM squared })_{i j}+\beta_{4 i}$ (missing fall vocabulary) $i j+r_{i j}$

Level 2-Classroom

$\beta_{0 j}=\gamma_{00}+\gamma_{01}$ (school district, urban fringe $\left.=1\right)+v_{0 i}$

$\beta_{1 j}=\gamma_{10}$

$\beta_{2 \mathrm{i}}=\gamma_{20}$

$\beta_{3 j}=\gamma_{30}$

$Y_{i j}$, which is the spring vocabulary, rhyming, sentence imitation or letter-word recognition score for child $i$ in class $i$, is a function of the respective coefficients $\left(\beta_{i}\right)$ at Level 1 as they pertain to child $i$ 's fall vocabulary, percent DDM linear trend, percent DDM squared, the quadratic trend, and whether or not the fall vocabulary score was missing, as well as a residual $\left(r_{i j}\right) . \beta_{0 ;}$ is a function of the fitted mean outcome score for the sample of students $\left(\gamma_{00}\right)$ taking into account shared classroom environment. $\gamma_{10}$ represents the mean score advantage for students attending the urban fringe district compared to the midsized city school district. $\gamma_{10}$ represents the effect of fall vocabulary on literacy. $\gamma_{20}$ represents the effect of percent DDM linear trend on literacy. $\gamma_{30}$ represents the effect of percent DDM quadratic trend on literacy. $\gamma_{40}$ represents the difference in mean outcome for children missing their fall vocabulary score relative to children with fall vocabulary scores. The error at the level of the classroom is represented by $u_{i}$. Residuals $(u, r)$ were assumed to be normally distributed with a mean of zero. 
Appendix D. Characteristics of children's AAE.

Figure D1. Distribution of African American English (AAE) types across sample in oral narrative elicitation; bars represent the number of times the $A A E$ feature was used.

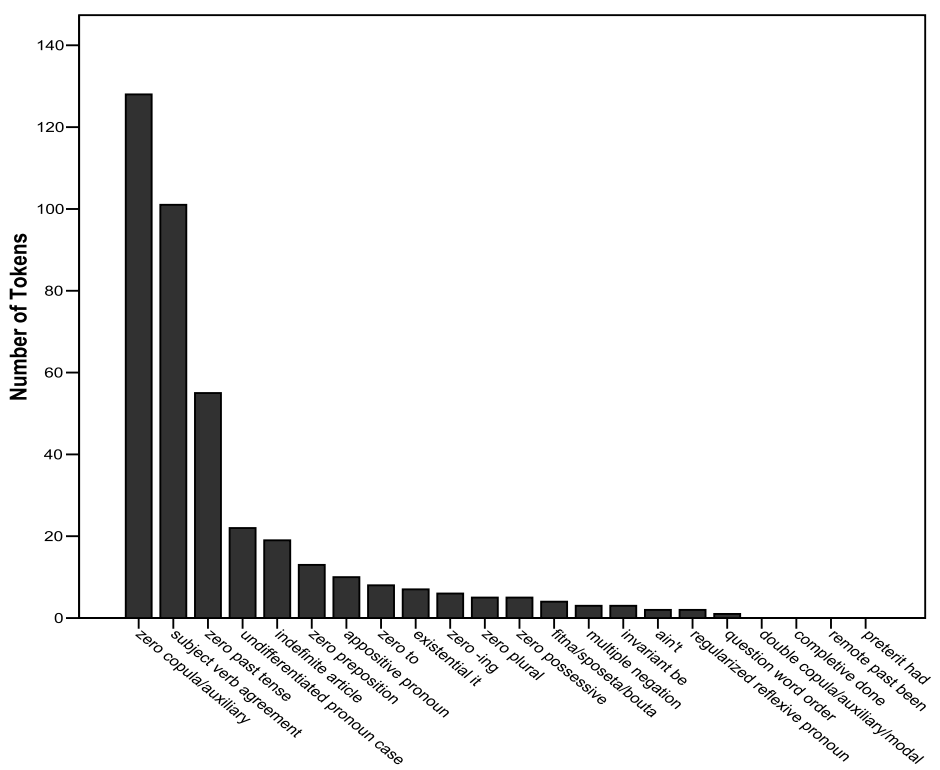

Figure D2. Proportion of children using each token type.

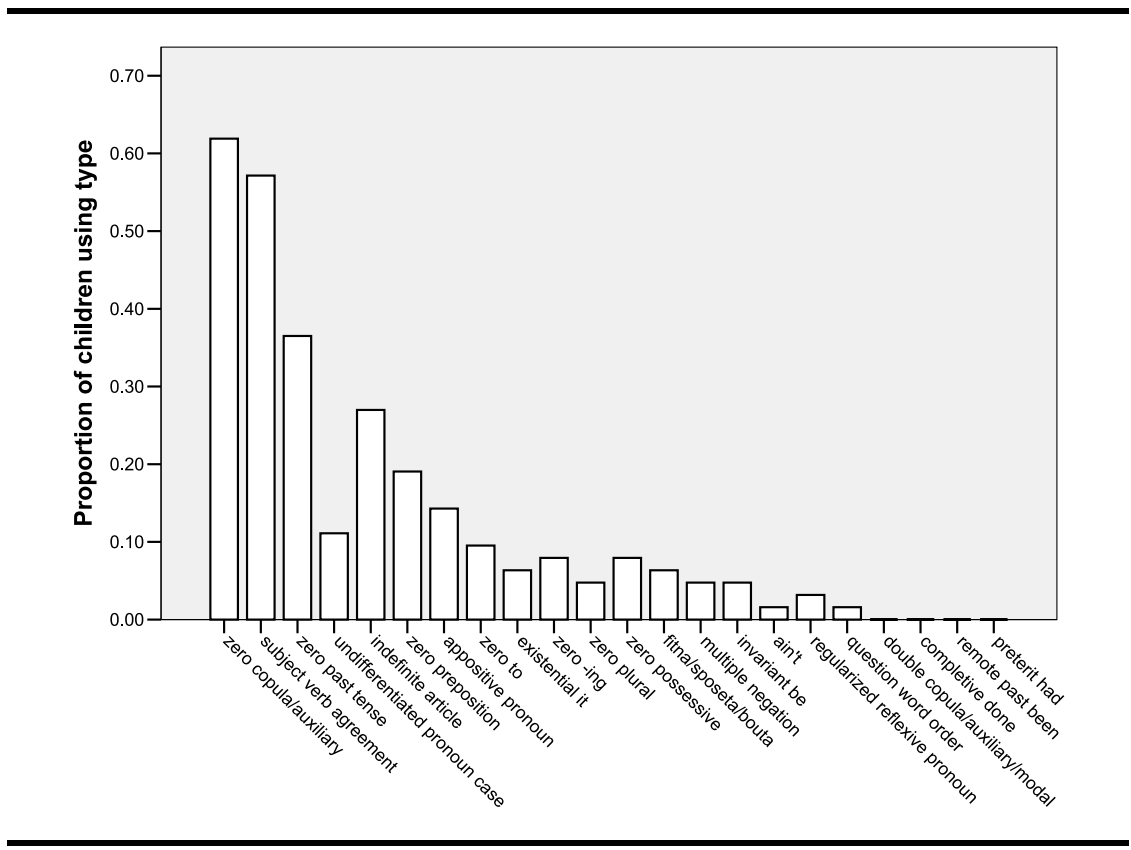


It has been hypothesized that teachers may hold negative perceptions and reduced expectations for students who use AAE (Goodman \& Buck, 1973), which may contribute to reduced academic achievement. This line of research revealed that teachers' perceptions of children's abilities and how they interacted with them was related to students' use of AAE (Brown, 1980; Shields, 1979; Washington \& Miller-Jones, 1989). For example, in one study, teachers listened to audiotapes of children speaking without any visual cues and were asked to rate their academic skills. Overall, teachers rated children who used more AAE as less able than children who used less or no AAE (Cecil, 1988). We conducted repeated observations of teacher-child interactions in their classrooms and administered teacher surveys designed to assess teachers' perceptions of their students and their own efficacy in meeting their needs. No teacher bias was evident for any of the 5 participating teachers. However, with only 5 teachers each teaching two classes, our power to find differences was severely limited. Our findings relate to these teachers only and cannot be generalized to teachers throughout the nation.

Classroom literacy practices were examined in a number of ways, using transcripts of teachers' and students' discourse (Connor, 2002). Classrooms were video- and audiotaped three times during March and April of 2001 across three contexts: circle time, book reading, and small group time. Tapes were transcribed (reliability $=92 \%$ agreement) and coded for references to explicit decoding activities and to other literacy references (see Connor, 2002). For example, the following teacher turn would be identified as a reference to explicit decoding:

Teacher: (pointing to the calendar) See those two letters $[t$ and $h]$ ? What are those two letters? They go together. They go /th/. Can you do that?

The following teacher turn would be coded as other literacy reference:

Teacher: Now this book isn't about birds. But there's a story later on that's about a bird. This is another book that's one of my favorites. This is called Harry the Dirty Dog.

In this case, the teacher is talking about literacy, but not explicitly about how to decode words. Only turns in which the teacher was specifically talking about reading, writing, books, and literacy were included. The variable, percent decoding references, was computed by dividing the number of teacher turns that included references to explicit decoding divided by all references to literacy (decoding plus other literacy references) multiplied by 100.

Additionally, teachers completed a questionnaire for each of the two classes they taught, which included items designed to solicit information regarding their beliefs about teaching young children how to read, their self-reported efficacy teaching children, and their perceptions of how disadvantaged the children were. Responses were on a 5-point Likert scale from strongly agree to strongly disagree.

Three questions differentiated teachers on their beliefs about literacy practices:

1. Developmentally appropriate practice is my primary approach to teaching preschoolers.

2. Children should not be taught to read until first grade, kindergarten at the earliest.

3. I teach phonics and letter-sound relationships.

Teachers who agreed or strongly agreed with Items 1 and 2 and disagreed or strongly disagreed with ltem 3 demonstrated a significantly lower percentage of decoding references than did teachers who responded with the opposite pattern $195 \%$ $\mathrm{Cl}$ decoding $=0,37.2 ; 95 \% \mathrm{Cl}$ other references $=43.2,90.2, F[1,8]=13.63, p=.006)$. Only the percent decoding reference variable was included in the analyses.

Teachers' questionnaires also solicited information on their perceptions of their students, including (a) many children in this class began the year not ready to read; (b) overall, the children in this class are starting at a disadvantage; and (c) all of the children in this class have the potential to learn. The Likert scale results were converted to a numeric score ( 5 = strongly agree; 1 = strongly disagree) by adding the teachers' responses to questions $a$ and $b$, then converting c ( 1 = strongly agree; $5=$ strongly disagree) and adding c, and then dividing by 3 . Thus, higher scores suggested that teachers perceived the children in their class to be more disadvantaged.

Teacher efficacy scores were computed in a similar manner. Scores for the following questions were added: (d) although teaching preschoolers is challenging, I have confidence that I can teach all of the children in this class and (e) I think I have made a difference in the lives of the students in this class. Scores for the following questions were converted $(1$ = strongly agree; 5 = strongly disagree) and then added: (f) teaching preschoolers at risk is difficult, $(\mathrm{g})$ teaching all of the children in this class is almost an impossible task. Teachers with higher scores reported that they felt more able to teach the children in their classes. Perceived student disadvantage and teacher efficacy were not significantly related $(r=-.37$, $p=.29)$, although power to detect moderate effects was limited by the small number of classes in the sample $(n=10)$.

Overall, teachers did not perceive the children in this sample to be disadvantaged (mean score of 2.8 on a scale of 1 to 5 , where 5 = highly disadvantaged). They also reported that they felt they would be somewhat effective in teaching them (mean score of 3.3 on a scale of 1 to 5 , where $5=$ highly effective). Generally, a substantial proportion of classroom literacy activities (over one third) were explicitly decoding focused, which included teaching children letters and phonological decoding (see Table E1). 
Appendix $E$ (p. 2 of 2). Teacher expectations.

Table E1 Teacher descriptive information.

\begin{tabular}{lccc}
\hline \multicolumn{1}{c}{ Teacher perceptions and practice } & Urban fringe & Midsized city & Total \\
\hline Number of classrooms & 4 & 6 & 10 \\
Teacher perceived efficacy $(M)$ & 3.5 & 3.2 & $3.30(1.16)$ \\
Teacher perception of child disadvantage (M) & 3.0 & 2.7 & $2.80(0.79)$ \\
Teacher percentage of decoding activities (M) & 51.95 & 27.87 & $37.50(31.66)$ \\
\hline
\end{tabular}

Note. Using HLM, we examined the relation between children's AAE use and teachers' perception of children's disadvantage, teachers' perceived efficacy teaching their students, and percentage of decoding activities, controlling for fall vocabulary and district. Only perception of child disadvantage related systematically to percent DDM, coefficient $=-1.07, t(5)=-2.639, p=.04$. This suggests that teachers were generally less likely to view children as disadvantaged if they used $A A E$ more frequently and were more likely to view children as disadvantaged if children used AAE less frequently. 